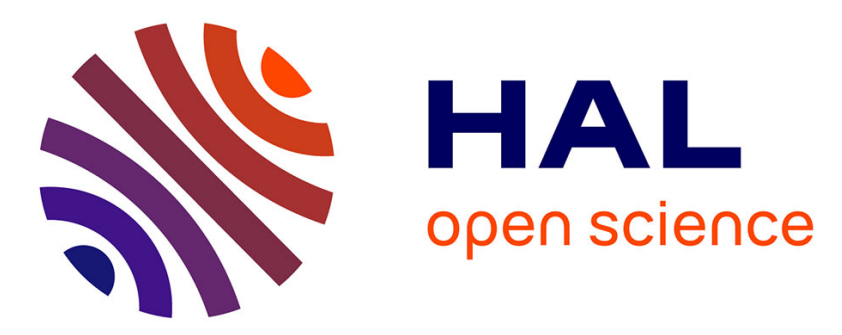

\title{
An Optimal Fuzzy Logic Power Sharing Strategy for Parallel Hybrid Electric Vehicles
}

Farid Khoucha, Mohamed Benbouzid, Abdelaziz Kheloui

\section{To cite this version:}

Farid Khoucha, Mohamed Benbouzid, Abdelaziz Kheloui. An Optimal Fuzzy Logic Power Sharing Strategy for Parallel Hybrid Electric Vehicles. IEEE VPPC 2010, Sep 2010, Lille, France. pp.1-5. hal-00578427

\section{HAL Id: hal-00578427 \\ https://hal.science/hal-00578427}

Submitted on 20 Mar 2011

HAL is a multi-disciplinary open access archive for the deposit and dissemination of scientific research documents, whether they are published or not. The documents may come from teaching and research institutions in France or abroad, or from public or private research centers.
L'archive ouverte pluridisciplinaire HAL, est destinée au dépôt et à la diffusion de documents scientifiques de niveau recherche, publiés ou non, émanant des établissements d'enseignement et de recherche français ou étrangers, des laboratoires publics ou privés. 


\title{
An Optimal Fuzzy Logic Power Sharing Strategy for Parallel Hybrid Electric Vehicles
}

\author{
F. Khoucha ${ }^{1,2}$, M.E.H. Benbouzid ${ }^{1}$ and A. Kheloui ${ }^{2}$ \\ ${ }^{1}$ University of Brest, EA 4325 LBMS \\ Rue de Kergoat, CS 93837, 29238 Brest Cedex 03, France \\ ${ }^{2}$ Electrical Engineering Department, Polytechnic Military Academy, 16111 Algiers, Algeria \\ E-mail: Mohamed.Benbouzid@univ-brest.fr
}

\begin{abstract}
Vehicle emission reduction has been a research objective for many years, by improving fuel economy and energy efficiency. Therefore, this paper presents a fuzzy logic controller for a Parallel Hybrid Electric Vehicle (PHEV). The PHEV required driving torque is generated by a combined contribution from an Internal Combustion Engine (ICE) and an Induction Motor (IM). The proposed Fuzzy Logic Controller (FLC) is designed based on the desired driving torque and the batteries State of Charge (SoC) with the objective to minimize fuel consumption and emissions, while enhancing or maintaining the PHEV driving performance characteristics. The fuzzy controller output controls the ICE throttle angle degree to achieve operation in a high efficiency region. The induction motor is sized to supply peak power to meet the load power requirement of the PHEV. The proposed PHEV fuzzy controller is implemented and simulated via the advanced vehicle simulator ADVISOR using the European urban (ECE-15) and sub-urban (EUDC) driving cycles. Simulation results reveal that the proposed fuzzy torque distribution strategy is effective over the entire operating range of the vehicle in terms of performance, fuel economy, and emissions.
\end{abstract}

Index Terms-Parallel Hybrid Electric Vehicle (PHEV), Internal Combustion Engine (ICE), Induction Motor (IM), State of Charge (SoC), Fuzzy Logic Control (FLC), power sharing strategy, ADVISOR.

\section{INTRODUCTION}

Due to environmental and energy constraints, electric vehicle (EV), hybrid electrical vehicle (HEV) and fuel cell electric vehicle (FCEV) have become one of the most viable alternatives solutions to conventional vehicles, which are driven only by internal combustion engines (ICE). HEV's include two energy converters to generate the power required to drive the vehicle and operate other electric accessories. Typically, the architecture of these vehicles includes an ICE with an associated fuel tank and an electric machine with an associated energy storage system (battery and/or ultracapacitor). Suitable management of power flow or distribution of torque is a critical issue for the implementation of HEV's. This task is performed by HEV control strategy. The HEV control strategy determines which power source must be used according to the driver's torque demand at a specific speed and the precise features of the driving situation. In other words, the control strategy is the algorithm according to which energy is produced, distributed and stored.
Researches in this field have clearly shown that fuzzy logic could be successfully applied to the design of HEV control strategies [1-7]. The main idea of these control strategies is usually based on the concept of load-leveling strategy, which attempts to operate the ICE in its efficiency peak point or its best fuel use at all times and uses the electric motor as a load-leveling device according to the state of charge of the energy storage system (battery and/or ultracapacitor). The structure and parameters of all these fuzzy control strategies are designed based on the designer acquaintance of the problem. While driving conditions and vehicle loads are highly nonlinear and can not be explicitly described, FLC strategy that has been designed based on engineering intuition frequently fails to achieve satisfactory overall system efficiency.

To face up to this difficulty, this paper presents an optimal fuzzy logic controller designed for a parallel HEV. The PHEV required driving torque is generated by a combined contribution from an Internal Combustion Engine (ICE) and an induction motor (IM). The proposed fuzzy logic controller is designed based on the desired driving torque $\left(T_{\text {Load }}\right)$ at a specific speed and the batteries SoC with the objective to minimize fuel consumption and/or emissions, while enhancing or maintaining the PHEV driving performance characteristics. The fuzzy controller output controls the ICE throttle angle degree to achieve operation in a high efficiency region. The IM is sized to supply peak power to meet the PHEV load power requirement. The proposed PHEV fuzzy controller is implemented and simulated via the advanced vehicle simulator ADVISOR using the European urban (ECE15) and sub-urban (EUDC) driving cycles.

\section{HEV CONFIGURATION AND CONTROL STRATEGY}

A PHEV incorporates two power drives, including an ICE and an IM. Therefore, it is the task of the PHEV control strategy to determine how to distribute the driver required torque between the ICE and the IM [8]. For positive torque requests, the sum of the engine and motor torques should be equal to the driver torque request. However, for negative torque request where the driver is braking, the engine torque is " 0 " and the sum of the motor and brake torques would be equal to the driver request. 
The PHEV control strategy is designed at several simultaneous targets such as minimization of Fuel Consumption (FC) and exhaust emissions ( $\mathrm{HC}, \mathrm{CO}$, and NOx). These aspects are often in conflict with each other, where the minimum fuel consumption does not necessarily result in the minimum emissions, which implies the need for an additional solution [9-10].

The main aim of the control strategy is that the vehicle must follow the driver request. This means that the total torque delivered by the ICE and the IM must be determined such that the driver torque requests (from brake and accelerator pedals) are consistently satisfied. The driver request is equivalent to the driving cycle. Therefore, control strategy must perform such that the driving cycle is adequately tracked. Another aim for the control strategy is its ability to allow extended drive ranges, acceleration and deceleration performances. Indeed, short drive range is obviously the most significant problem with current battery EVs [11]. EVs drive range can be extended by improving battery energy performance, increasing the efficiency of the propulsion motors and the power electronics interface, or recovering regenerative braking energy.

One of the other constraints for control strategy is to remain charge-depleting. This constraint forces the battery to work with a minimum of SoC in order to allow the braking energy recovery. It should be noted that in addition to the above constraints, there are also some physical constraints such as ICE torque limits, electric motor torque limits, and battery power limits. These limits are hard constraints that cannot be violated. In this study, these constraints are imposed on the component models.

\section{FUZZY LOGIC CONTROL STRATEGY}

Intelligent control such FLC has become more and more popular as the modern computers capabilities have considerably increased. Fuzzy logic was chosen because it can handle both nonlinear data and linguistic knowledge [12].

\section{A. The FLC Bases}

The fuzzy logic controller can accomplish the same task more efficiently and without the use of lookup tables or interpolation. The main objective of this controller is to force the ICE to work in the vicinity of its optimal operating points. The optimal operating points are determined based on ICE parameters at the current vehicle speed so as to minimize instantaneous fuel consumption and emissions for all torques at the current speed are taken from the engine maps (Fig. 1). At any particular point in time, the ICE speed is determined based on the powertrain configuration and the current gear ratio. This is the speed at which instantaneous optimization is performed. For the current speed, all possible torques provided by the ICE are considered. Afterwards the fuel consumption and emissions for all torques at the current speed are taken from the engine maps and the following cost function is calculated for all points (1).

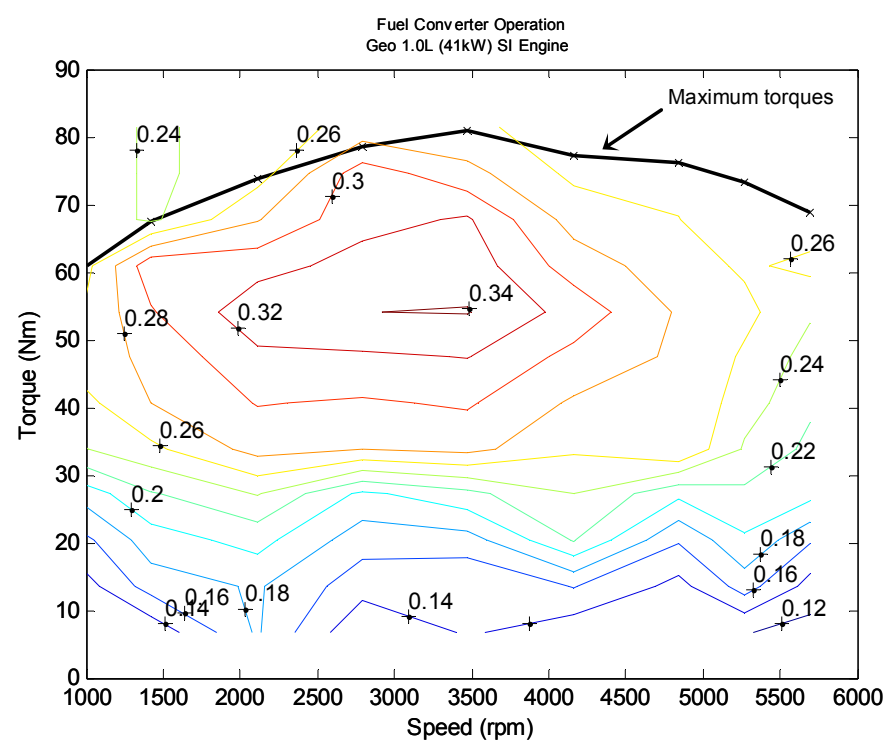

Fig. 1. ICE efficiency map and optimal curve.

$$
j=\frac{1}{w_{1}+w_{2}+w_{3}}\left(w_{1} \frac{F C}{\overline{F C}}+w_{2} \frac{H C+N O_{x}}{\overline{H C+N O_{X}}}+w_{3} \frac{C O}{\overline{C O}}\right)
$$

in which $\overline{F C}, \overline{H C+N O_{x}}, \overline{C O}$, are the target values used to normalize each variable. The target value for fuel consumption can be defined by the designer and for the emission target values; the standards of tailpipe emissions can be used. $\left(w_{1}, w_{2}, w_{3}\right)$ are relative weights assigned to each parameter based on the importance level. This is a large degree of freedom and the weights must be selected based on the objectives (vehicle mission). Assigned by the designer for instance, when the main objective is the minimization of the vehicle fuel consumption, the $F C$ weight is set to " 1 " and the weights of emissions will be set to " 0 ". The optimal operating point at the current speed is the one with the lowest cost function value. If the optimal operating points are plotted for all speeds, the optimal curve will be achieved. In this study, the optimal curve for particular weights is shown in Fig. 2. It is worth mentioning that this optimal curve is obtained for a particular ICE temperature. When the ICE temperature varies, the maps are corrected based on the new temperature, and the shape of the optimal curve changes. The calculated optimal operating point (the ICE operation points will be forced in the vicinity of the best point of efficiency maps) is an ideal operating point. However, the actual torque delivered by the ICE should be determined in a manner such that the driver torque requests (from brake and accelerating pedals) are satisfied consistently, and the battery SoC is maintained around a minimal junction at all times to recover energy during braking. Therefore, the actual torque of the ICE is computed by the FLC based on the previously calculated optimal operating point of the ICE, driver torque request and the battery SoC for each vehicle speed. 


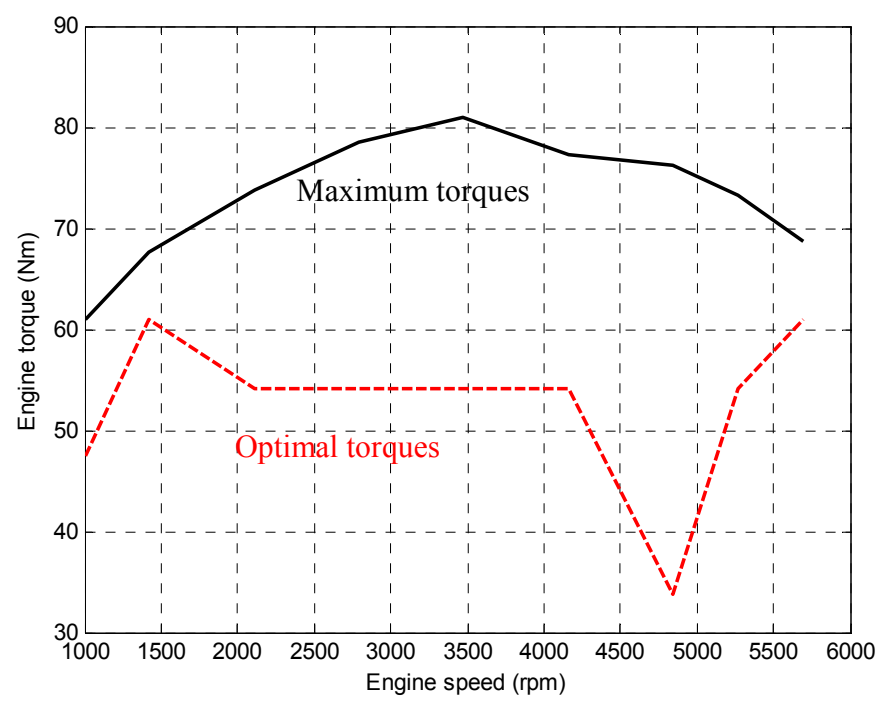

Fig. 2. Optimal torque curve for particular weights.

It should be noted that the actual ICE output torque delivered to the torque coupler could be very different from the FLC command. The remaining torque at that speed, required to meet driver command, is provided by the induction motor. The IM may produce either positive or negative torque (acceleration and braking mode).

Figure 3 schematically illustrates the proposed fuzzy logic control strategy.

\section{B. The FLC Structure}

When designing an FLC, two main parts must be determined: structure (input and output variables, fuzzy rules structure, number and type of Membership Functions (MFs), the inference mechanism type, operators, and defuzzification method) and parameters (related to MFs and fuzzy rules) [12].

In this study, the FLC is a Mamdani type fuzzy system. The required torque and $\mathrm{SoC}$ at each time are considered as the FLC inputs. It should be noted that the optimal torque is not an input for the FLC and is only used to scale the MFs at each time step. FLC output is the scaled value of the actual output torque from the ICE that must be scaled back later.
The logical AND has been implemented with the minimum operator, the implication method is minimum, the aggregation method is maximum, and the defuzzification method is centroid [12].

Similarly, the SoC is scaled from "0" to " 1 "; "0" corresponding to the lowest SoC limit and " 1 " corresponding to the highest SoC limit. The lowest and the highest SoC limits are determined according to the battery pack characteristics as shown in Fig. 4. It is advantageous to maintain the $\mathrm{SoC}$ near a target value during the driving cycle [9]. This target value is selected to be as close as possible to the minimum charge and discharge resistances of the battery. The lowest and highest SoC limits should be close to this target value. For instance, the charge and discharge resistance curves of the lead-acid battery used in this study are shown in Fig. 4. For this case, the target value is set to 0.63 , the lowest $\mathrm{SoC}$ to 0.6 and the highest to 0.7. In SoC scaling, 0.52 represents the target value. The output torque MFs are exactly the same as those for the required torque. The justification is that MFs of the required torque are defined based on the ICE characteristics and the FLC output is the output torque of the same ICE.

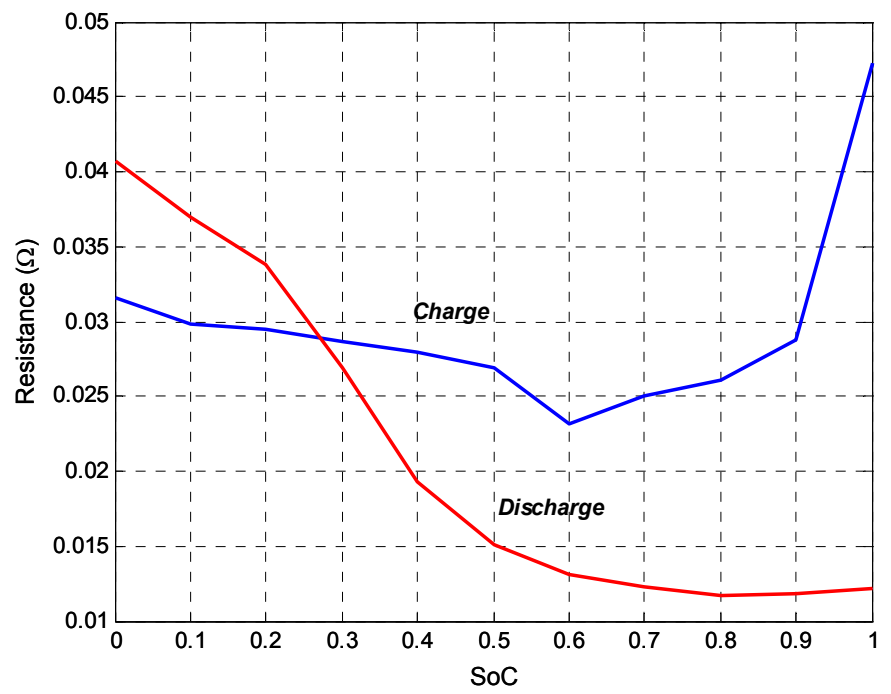

Fig.4. Charge and discharge resistances of the battery.

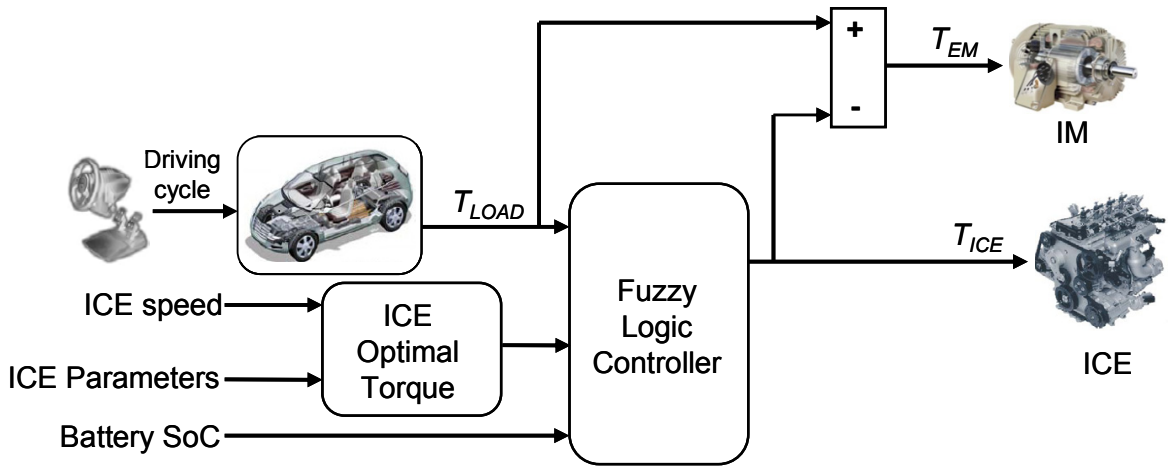

Fig. 3. Schematic of the proposed fuzzy control strategy. 


\section{ADVISOR-BASED SIMULATION RESULTS}

In this section, we present the implementation and the simulation study for the evaluation of the proposed PHEV fuzzy logic control strategy for the vehicle energy management. In this case the advanced vehicle simulator ADVISOR is used to carry-out the simulations with the European urban (ECE-15) and sub-urban (EUDC) driving cycles (Fig. 5) [13-14]. The proposed energy management strategy performances are illustrated by Figs. 7 to 9 .

Figures 7 and 8 show the ICE and the IM operating points (efficiency maps). The operating points in Fig. 7 are close to the optimal curve. This indicated that the ICE is operated close to the optimal efficiency compared to a conventional vehicle as illustrated by Fig. 6 .

The IM operating points are mainly in the optimal speed range of 1500-5500 rpm (Fig. 8).

For illustration, Fig. 9 shows the PHEV battery SoC during the driving cycles illustrated by Fig. 5 .

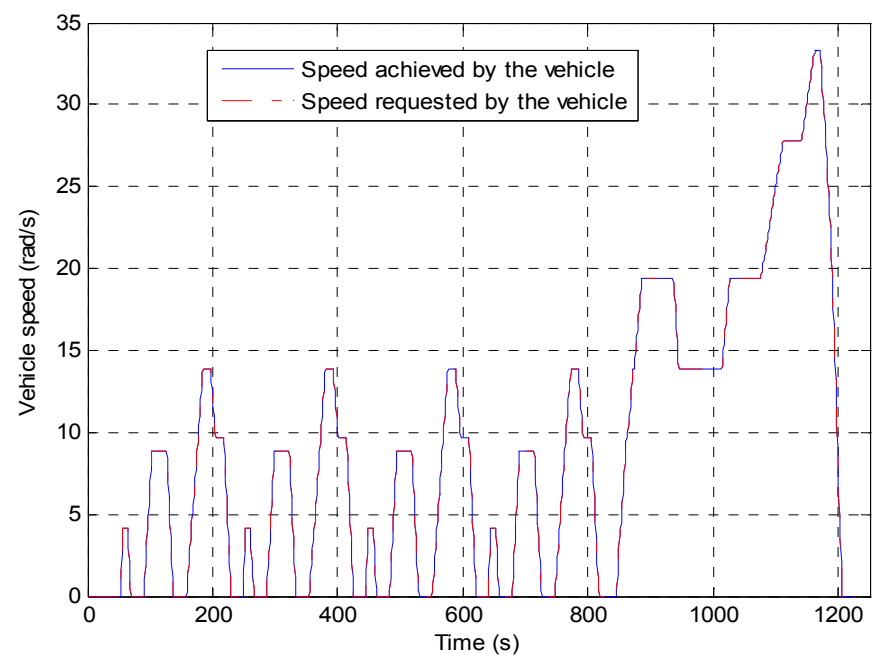

Fig. 5. The PHEV European urban (ECE-15) and sub-urban (EUDC) driving cycles.

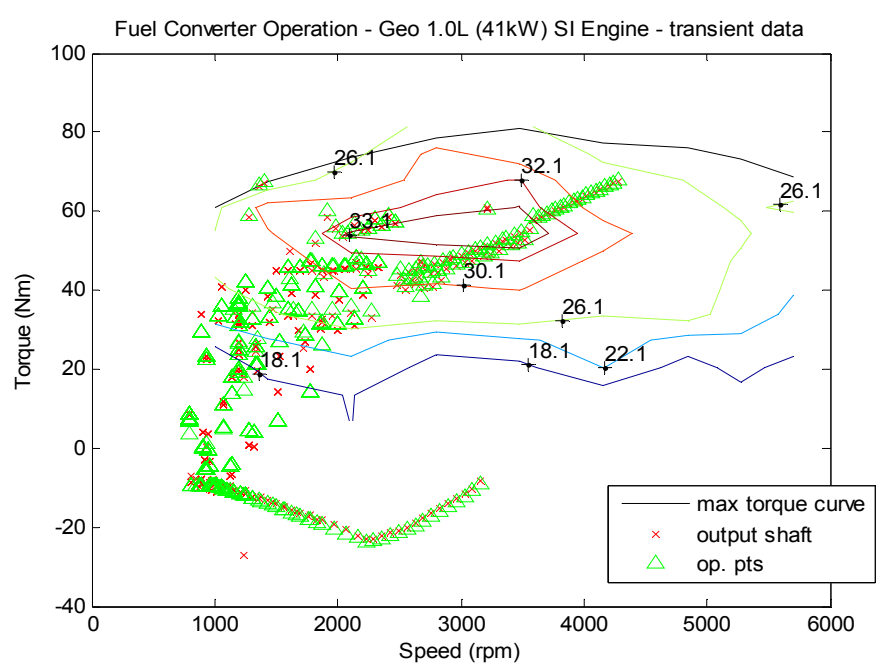

Fig. 6. Conventional vehicle operating efficiency maps.

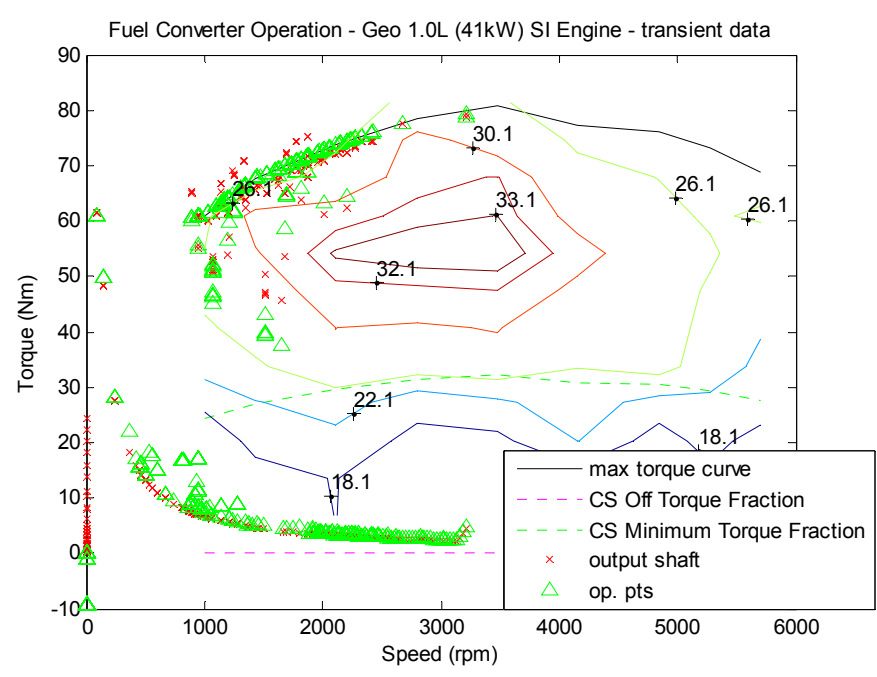

Fig. 7. PHEV ICE operating efficiency maps.

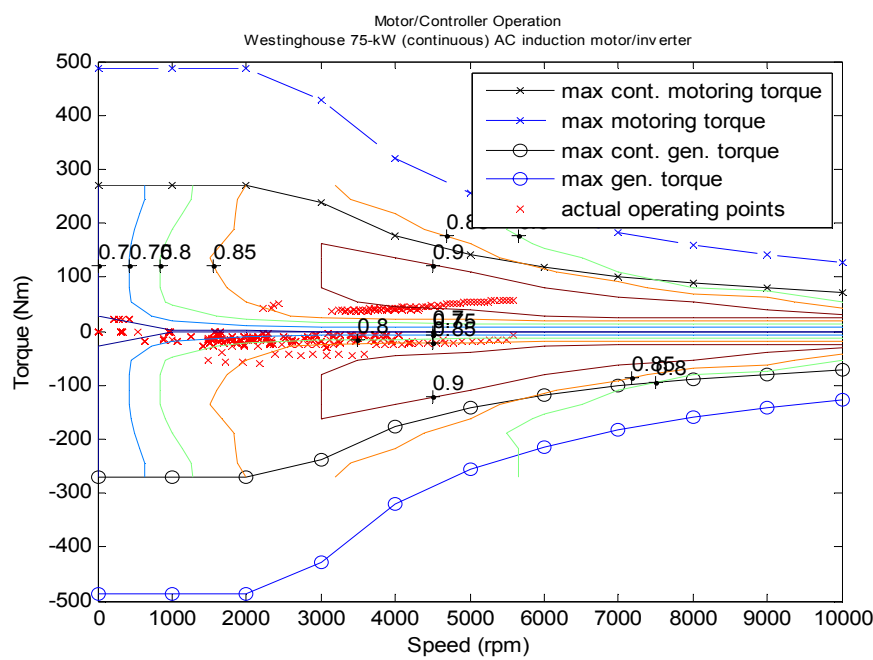

Fig. 8. PHEV IM operating efficiency maps.

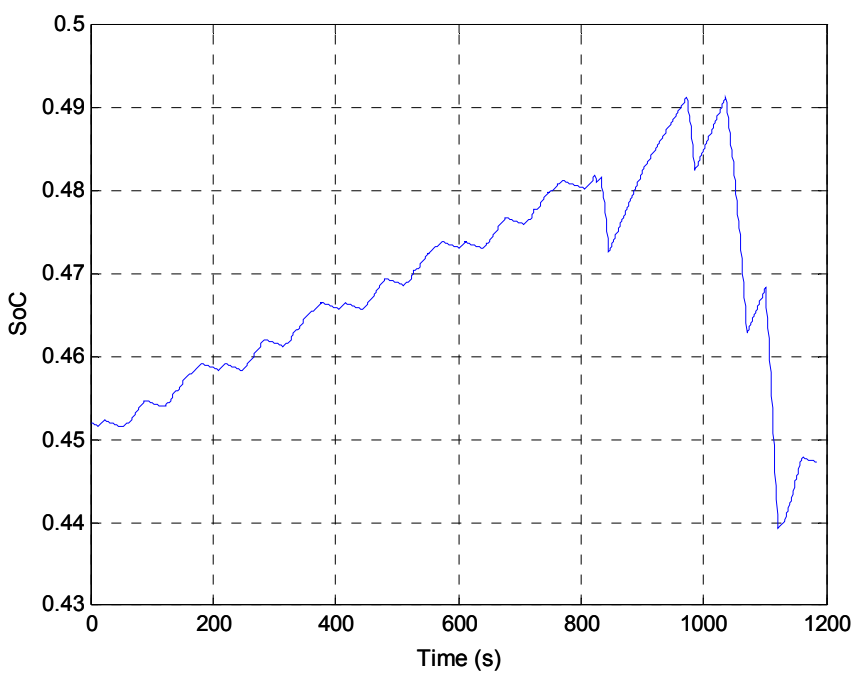

Fig. 9. PHEV battery SoC. 
It should be mentioned that the proposed controller only optimizes the ICE efficiency, and does not optimize the IM, the battery or the transmission efficiencies. In fact, it optimizes the ICE efficiency by adjusting both the ICE speed (using the transmission gear ratio) and torque to make the operating point as close as possible to the optimal curve.

\section{CONCLUSION}

This paper has presented a fuzzy logic-based controller for a parallel hybrid electric vehicle. This controller has been designed to achieve the PHEV optimal power management with the main objective to minimize fuel consumption and emissions, while enhancing or maintaining the PHEV driving performance characteristics. In this case, the vehicle required driving torque is generated by a combined contribution from the ICE and an induction motor. Indeed, the efficiency maps of these two components have been used to design the controller.

The power controller first converts the driver accelerator and brake pedal inputs to a driver power command. The driver power command, the battery SoC, and the induction motor speed are then used by the proposed fuzzy logic controller to compute the optimal vehicle power and a scaling factor for the electric motor (IM). The driver power command, the optimal power, and the scaling factor are afterwards used to compute the optimal ICE and IM powers. Furthermore, the ICE efficiency for a given power level is optimized using an optimal speed-torque curve, and using gear shifting to control the speed of the ICE.

The power controller ensures that the driver inputs (from brake and accelerator pedals) are consistently satisfied, the battery is sufficiently charged during driving cycles, and the PHEV fuel consumption is optimized.

The proposed PHEV fuzzy controller has been implemented and simulated via the advanced vehicle simulator ADVISOR using the European urban (ECE-15) and sub-urban (EUDC) driving cycles. Simulation results reveal that the proposed fuzzy torque distribution strategy is effective over the entire operating range of the vehicle in terms of performance and fuel economy.

\section{REFERENCES}

[1] S.R. Salmasi, "Control strategies for hybrid electric vehicles: Evolution, classification, comparison, and future trends," IEEE Trans. Vehicular Technology, vol. 56, n5, Part. 1, pp. 2393-2404, September 2007.

[2] A. Sciarretta and L. Guzzella, "Control of hybrid electric vehicles: Optimal energy management strategies," IEEE Control Systems Magazine, vol. 27, n², pp. 60-70, April 2007.

[3] A.A. Ferreira, J.A. Pomilio, G. Spiazzi, L. de Araujo Silva, "Energy management fuzzy logic supervisory for electric vehicle power supplies system," IEEE Trans. Power Electronics, vol. 23, n¹, pp. 107-115, January 2008.

[4] J.S. Won, R. Langari, and M. Ehsani, "An energy management and charge sustaining strategy for a parallel hybrid vehicle with CVT," IEEE Trans. Control Systems Technology, vol. 13, n², pp. 313-320, March 2005.

[5] J.S. Won and R. Langari, "Intelligent energy management agent for parallel hybrid vehicle-Part II: torque distribution, charge sustenance strategies, and performance results," IEEE Trans. Vehicular Technology, vol. 54, n³, pp. 935-953, May 2005.

[6] B.M. Baumann, G. Washington, B.C. Glenn and G. Rizzoni, "Mechatronics design and control of hybrid electric vehicles," IEEE/ASME Trans. Mechatronics, vol. 5, $\mathrm{n}^{\circ} 1$, pp. 58-72, March 2000.

[7] N.A. Kheir, M.A. Salman and N.J. Schouten, "Emissions and fuel economy trade-off for hybrid vehicles using fuzzy logic," Mathematics and Computers in Simulation, vol. 66, n²-3, pp. 155-172, June 2004.

[8] J.S. Won and R. Langari "Fuzzy torque distribution control for a parallel hybrid vehicle," Expert Systems, vol. 19, n²1, pp.4-10, December 2002.

[9] M. Ehsani, Y. Gao, S.E. Gay, A. Emadi, Modern Electric, Hybrid Electric, and Fuel Cell Vehicles: Fundamentals, Theory, and Design. CRC Press, 2004.

[10] S. Delprat, J. Lauber, T.M. Guerra, and J. Rimaux, "Control of a parallel hybrid powertrain: optimal control," IEEE Trans. Vehicular Technology, vol. 53, n³, pp. 872-881, May 2004

[11] N.J. Schouten, M.A. Salman and N.A. Kheir, "Energy management strategies for parallel hybrid vehicles using fuzzy logic," Control Engineering Practice, vol. 11, pp. 171-177, February 2003.

[12] J.M. Mendel, "Fuzzy logic systems for engineering: A tutorial," IEEE Proceedings, vol. 83, n³, pp. 345-377, March 1995.

[13] D.W. Gao, C. Mi and A. Emadi, "Modeling and simulation of electric and hybrid vehicles," Proceedings of the IEEE, vol. 95, n 4 , pp. 729 745, April 2007.

[14] ADVISOR 2004 - Virtual Vehicle Analysis http://www.avl.com/. 